\title{
MÁRIO DE SÁ-CARNEIRO, SEM ANOS DEPOIS
}

\author{
Paula Cristina Costa*
}

\author{
Universidade Nova de Lisboa
}

Resumo: A obra de Mário de Sá-Carneiro ainda se mantém actual cem anos depois da sua morte: a modernidade do seu estilo não se esgota nas modas modernistas da época, mas mantém-se actual e contemporânea dos dias de hoje. Esta obra é de uma grande coerência temática. Ao longo da sua poesia, prosa e teatro, repete-se renovadamente o tema do Eu/Outro, o desejo de atingir a perfeição absoluta, como Ícaro, e o fracasso da realização plena. Em textos como os bem conhecidos poemas «Quasi», e «7》 assim como na narrativa «A Confissão de Lúcio», está presente este desejo de fusão do $\mathrm{Eu}$ e do Outro e a impossibilidade de o conseguir. Mário de Sá-Carneiro foi, juntamente com Pessoa, um dos fundadores do modernismo português, um dos directores da revista «Orpheu». Ambos os poetas criaram ismos fundamentais para a construção do nosso modernismo: paulismo, interseccionismo, sensacionismo. No entanto, mantiveram-se fiéis aos seus estilos próprios.

Palavras-chave: Sá-Carneiro. Eu/Outro. Modernismo. Contemporâneo.

\section{Mário de Sá-Carneiro, sem anos depois}

Cem anos depois da morte de Mário de Sá-Carneiro, a sua obra continua viva e sem idade. Poucos poetas terão partido tão cedo, «saltado na bruma, a correr no azul à busca da beleza», (SÁ-CARNEIRO, 1996, p. 27) ${ }^{1}$ como este poeta de «Partida». Poucos poetas permanecem tão jovens, tão sem idade na nossa memória. Não só porque se suicidou aos 26 anos (incompletos) de idade, mas também porque a sua obra poética continua suspensa num sem tempo, num fora do tempo que a define como contemporânea de todos os tempos.

De romântica a cubista-interseccionista, de simbolista-decadente a futuristasensacionista, a obra do poeta de «Quasi» representou todos estes ismos, encenou tendências diversas e aparentemente contraditórias. Como se o poeta tivesse pressa de representar todos esses papéis ou personagens para depois poder escolher qual aquele que mais the agradava, ou em qual personagem se sentiria mais confortável. Mas não teve tempo de escolher. Ou porque os deuses não lhe concederam esse tempo - «Morre jovem o que os deuses amam» (PESSOA, 1924) -, ou porque ele próprio não se quis conceder esse tempo. E é também este sem tempo

\section{Esta obra está licenciada sob uma Creative Commons - Atribuição 4.0}

\footnotetext{
* Professora no Departamento de Estudos Portugueses da Faculdade de Ciências Sociais e Humnas da Universidade Nova de Lisboa. E-mail<paula.cristina.costa@hotmail.com>.

${ }_{1}^{1}$ «O que devemos é saltar na bruma, / Correr no azul à busca da beleza.», «Partida».
} 
de vida que o conseguirá manter para sempre como um devir, que nunca correrá o risco de se tornar obsoleto, anacrónico ou uma paródia de si mesmo.

Mário de Sá-Carneiro viveu uma vida de relâmpago, não de um relâmpago de nada, mas de um relâmpago de tudo. Assim também as suas personagens: elas são intensas e desafiam todos os limites, todos os abismos. São Ícaros de ambição e desejo máximo: ou tudo ou nada, mesmo que esse tudo implique sacrificar a vida, aproximá-la demasiado do fogo, de um qualquer «céu em fogo», como promessa de um instante supremo de perfeição, do belo absoluto, de uma apoteose ou de uma qualquer revelação do mistério. Todas as personagens da sua obra anseiam por vivências hiperbólicas, são Ícaros desmedidos que não temem o risco e o abismo. São personagens que desejam alcançar os céus, tocar a luz, o sol, a linha de todos os horizontes. O próprio poeta o confessou a Pessoa, numa das suas cartas: «Eu sou daqueles que vão até ao fim.» (SÁ-CARNEIRO, 2001, p. 33). ${ }^{2}$ E foi.

Quando relemos toda a sua obra, poesia e prosa, facilmente percebemos que este é um dos dramas mais vividos quer pelo eu poético quer pelas personagens ficcionais de SáCarneiro. Por exemplo, na narrativa «A Confissão de Lúcio», a tensão dramática vivida entre Ricardo, Lúcio e Marta, é exemplar no modo como põe em cena o desejo de atingir, possuir o outro, como modo (im)possível de atingir a perfeição suprema. É bem conhecido este enredo: o dramaturgo Lúcio Vaz (espécie de clone de Sá-Carneiro) projecta a sua alteridade no poeta Ricardo Loureiro. Este «poeta das brasas» representa o ideal do eu, do artista a que Lúcio e Sá-Carneiro aspiram: rapaz louro e belo, poeta bem sucedido, dotado de uma enorme sensibilidade poética e duma plena compreensão da alma de Lúcio. Enfim, uma «criatura superior - genial, perturbante.» (SÁ-CARNEIRO, 1998, p. 43). Todo o drama desta narrativa se desenrola em torno do desejo do Eu possuir o Outro, ou seja, de Lúcio possuir Ricardo e vice versa. Posse impossível de se concretizar sem que uma mulher, Marta, mulher de Ricardo, sirva de intermediária, como vértice do triângulo amoroso, ao se tornar amante de Lúcio. No final da narrativa e antes da tragédia final, já se adivinha que a identificação entre Lúcio e Ricardo é total e que são duplos um do outro, num contínuo desdobramento ao longo da sua amizade. Com a suposta morte de Ricardo e o desaparecimento súbito da misteriosa mulher que é Marta, subsiste a dúvida, ou reforça-se o realismo mágico desta narrativa quem matou Ricardo? Lúcio? Quem é Marta? Como diria a segunda veladora do «drama estático» de Pessoa, «O Marinheiro»: «Que pena se alguém pudesse responder...» (PESSOA, 1989, p. 31).

\footnotetext{
${ }^{2}$ Carta datada de 21 de janeiro de 1913.
} 
«A Confissão de Lúcio» é, sem dúvida, a ficção por excelência de Sá-Carneiro onde este drama da alteridade fracassada está exemplarmente representado. Mas a verdade é que antes do «fracasso» estas personagens voam bem alto no sonho de atingirem o seu objectivo supremo. Também elas, à imagem do seu autor, «são daquelas que vão até ao fim», mesmo que esse fim signifique, como a Ícaro, sacrificarem-se às suas próprias mãos. Ou como a Narciso, afogar-se no lago que reflecte a imagem de si mesmo, na ilusão de um outro que se desejaria ver/ser. «Narciso em sacrifício», chamou-lhe Fernando Paixão (2003), num ensaio sobre a poética de Sá-Carneiro, lendo-a, como outros autores o fizeram antes, à luz deste mito. Do encantamento inicial ao desfecho cruel, também este Narciso «agoniza a perda do sonho. Em seu lugar, impera o desencanto e a vertigem da queda.» (PAIXÃO, 2003, p. 64).

Entre a disforia e a euforia, entre a realidade e o sonho ou entre o spleen e o idéal, para parafrasear um título bem conhecido de Baudelaire, a poética de Sá-Carneiro movimenta-se em espirais de sentido com uma exemplar coerência temática. Da poesia ao conto, à novela, ao teatro, os mesmos temas reescrevem-se e, como verdadeiros vasos comunicantes, fazem desta obra um círculo perfeito. Para além do tema modernista por excelência, da insatisfação e dispersão do eu, do estilhaçamento do eu em outros de si mesmo, a poética de Sá-Carneiro agrava este sentimento de insatisfação do eu e explora até ao limite o tema do drama da posse do outro. Para além da narrativa emblemática do desenvolvimento deste aspecto que é o romance «A Confissão de Lúcio», também em muitos outros textos do autor podemos encontrar a reescrita deste tema. Por exemplo, no poema «7», publicado em «Orpheu»I:

Eu não sou eu nem sou o outro,

Sou qualquer coisa de intermédio:

Pilar da ponte de tédio

Que vai de mim para o outro. (SÁ-CARNEIRO, 1996, p. 80),

ou logo na primeira estrofe do poema «Quasi»:

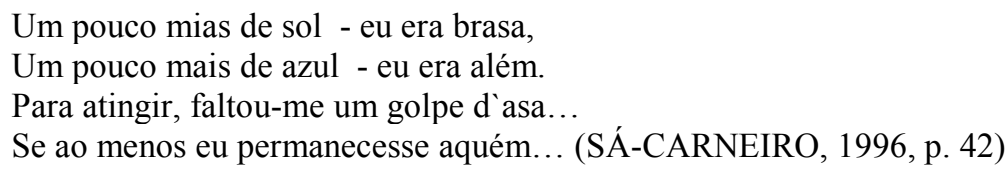

Estes são apenas mais dois dos muitos exemplos possíveis de toda uma poética que aspira à posse do outro, ou fusão suprema do eu e do outro num instante feliz. Sem receio de arriscar a vida para atingir este instante supremo de perfeição, todas as personagens são personagens suicidas, personagens que morrem em palco às suas próprias mãos, num ímpeto de desencanto e agonia face à impossibilidade de realização desse sonho. Encenando este 
drama do fracasso da alteridade e contaminando com ele a própria vida, entendida como palco duma representação do eu na distância do(s) outro(s), toda a obra de Sá-Carneiro «é a representação do eu como lugar de representação», (MARTINS, 1996, p. 11) nas palavras de Fernando Cabral Martins, o que na opinião do mesmo ensaísta, o transforma num actor mais do que num autor, num actor que maioritariamente representa a personagem do poeta (MARTINS, 1996, p. 11).

Relendo, hoje, cem anos depois, a obra poética do poeta de «Quasi», percebemos que para Mário de Sá-Carneiro ser moderno, era muito mais do que ser modernista, estar à la page das vanguardas europeias. Ser moderno era sobretudo viver o jamais vivido, sentir o jamais sentido, abraçar um estilo próprio na urgência da vertigem da mudança, de todas as mudanças a que o poeta assistia a um ritmo vertiginista. Esta modernidade inerente ao seu verdadeiro modo de ser e não apenas a uma moda ou ao «prazer fugitivo da circunstância», como diria Baudelaire ${ }^{3}$, é o que situa a sua obra num sem tempo, numa permanente intempestividade.

É neste desfasamento ou não coincidência total com o seu tempo que a obra de SáCarneiro ganha tempo, projecta-se como contemporânea de outros tempos. Sá-Carneiro continua, hoje, a poder ser lido como um autor contemporâneo, no sentido em que Agamben define o autor contemporâneo: como aquele que se consegue aproximar e distanciar simultaneamente do seu tempo: «Aquele que pertence deveras ao seu tempo, que é deveras contemporâneo é alguém que não coincide perfeitamente com ele nem se adapta às suas exigências e é por isso, nesse sentido, inactual.» (AGAMBEN, 2010, p. 20).

De facto, é sabida a enorme responsabilidade de Sá-Carneiro na criação do modernismo português. Lado a lado com o seu compagnon de route Fernando Pessoa, é da amizade e cumplicidade poética entre os dois que nasce o entusiasmo pela criação dos vários ismos que irão constituir o modernismo português: o paúlismo, o interseccionismo e o sensacionismo. Com o privilégio de ter podido assistir ao nascimento das vanguardas do início do século em Paris, nomeadamente, do cubismo e do futurismo, é Sá-Carneiro quem vai dando notícia destas novidades, por carta, a Pessoa. Na partilha destas novas experiências poéticas, Pessoa cria os três ismos seguidos da criação dos três heterónimos. Do díptico «Impressões do Crepúsculo» ao solitário poema «Paúis», como ficou rapidamente conhecido, de «Chuva Oblíqua» às Odes futuristas de Álvaro de Campos, estavam criados os principais

\footnotetext{
${ }^{3}$ É bem conhecida a forma como Baudelaire definiu a modernidade: como aquela que consegue «extrair o eterno do transitório», aquela que é «o transitório, o fugitivo, o contingente, a metade da arte, cuja outra metade é o eterno e o imutável.» (BAUDELAIRE, 2006, p. 21).
} 
ismos pessoanos do modernismo português. Mas a criação destes ismos por parte de Pessoa, e quem sabe senão também dos heterónimos, talvez nunca tivesse acontecido sem a cumplicidade de Sá-Carneiro. Ao relermos as cartas do poeta em Paris trocadas com o poeta em Lisboa, percebemos como foi importante toda a informação veículada por Sá-Carneiro a Pessoa, sobre Picasso e o cubismo, sobre Marinetti e o futurismo italiano. Conversas em torno da Arte e do artista, apreciações literárias feitas reciprocamente aos textos que ambos enviavam um ao outro, entre outros aspectos, terão sido decisivos para o entusiasmo com que os dois poetas sonharam a criação de uma revista literária em Portugal que fosse essa ponte entre Portugal e a Europa. A revista aconteceu: «Orpheu». Nela se juntaram muitos outros poetas e artistas que sonhavam também acordar Portugal, «a dormir desde Camões» ${ }^{4}:$ Almada Negreiros, Santa-Rita Pintor, Amadeo de Souza-Cardoso (previsto colaborar num 4 número da revista que nunca se concretizou), Luiz de Montalvôr, Ronald Carvalho, Ângelo de Lima, Raúl Leal e muitos outros que se juntaram e constituíram este grupo de «Orpheu»... Mas SáCarneiro foi o intermediário fundamental para que «Orpheu» se concretizasse. Não apenas por ter sido o seu pai que financiou os dois primeiros números da revista publicados, mas sobretudo porque com um entusiasmo desmedido, a sonhou e preparou à distância com Pessoa.

No entanto, apesar de todo este fascínio pelas vanguardas e deste desejo pelo novo, a poética de Sá-Carneiro, à semelhança da de Pessoa, não se esgota nessas modas parisienses mais ou menos circunstanciais ou fugidias. Se temos poemas cubistas-futuristasinterseccionistas, como «Manucure», por exemplo, também temos outros como «Apoteose» e «Distante Melodia...» ou «Taciturno», de um misto de neo-simbolismo paúlico mitigado com um decadentismo à Camilo Pessanha. É também deste hibridismo que resulta a riqueza da sua poética. E é também esta capacidade de ser moderno, sem se esgotar em modas modernistas, que faz de Sá-Carneiro um poeta contemporâneo, (in)actual cem anos depois.

\section{Referências}

AGAMBEN, Giorgio. O que é o Contemporâneo?. In.: . Nudez. Trad. de Miguel Serras Pereira, Lisboa: Relógio d'Água, 2010.

BAUDELAIRE, Charles. A Modernidade. In.: . O Pintor da vida moderna. 4.ed. Trad. de Teresa Cruz. Lisboa: «Passagens», Vega, 2006.

\footnotetext{
4 Trata-se de uma das afirmações simbólicas proferidas por Almada Negreiros no seu famoso «Ultimatum futurista às gerações portuguesas do século XX». Portugal Futurista (1981, p. 36).
} 
MARTINS, Fernando Cabral. Prefácio a «Mário de Sá-Carneiro, Poemas Completos». Martins. Lisboa, Assírio Alvim, 1996.

NEGREIROS, Almada. Ultimatum futurista às gerações portuguesas do século XX. Portugal Futurista. Lisboa: Contexto, 1981.

PAIXÃO, Fernando. Narciso em sacrifício. A poética de Mário de Sá-Carneiro. São Paulo: Ateliê Editorial, 2003.

PESSOA, Fernando. Mário de Sá-Carneiro (1890-1916). Athena: revista de arte, Lisboa, n. 2, Nov. 1924. Disponível on-line em: <http://purl.pt/22125>. Acesso em 24 set. 2016.

. O Marinheiro. In.: Orpheu I, Lisboa: Ed. Contexto, 1989.

SÁ-CARNEIRO, Mário de. A Confissão de Lúcio. Edição de Fernando Cabral Martins. Lisboa, Assírio \& Alvim, 1998.

Cartas de Mário de Sá-Carneiro a Fernando Pessoa. Edição de Manuela Parreira da Silva. Lisboa, Assírio \& Alvim, 2001. 1996.

. Poemas Completos. Edição de Fernando Cabral Martins. Lisboa, Assírio Alvim,

[Recebido em 27 de julho de 2016 e aceito para publicação em 8 de agosto de 2016]

\section{Mário de Sá-Carneiro, 100 years later}

Abstract: Mário de Sá-Carneiro's work is still current even hundred years after his death: the modernity of his style is not limited to the modernist fashions of the time, but remains contemporary of today. This work has a large thematic coherence. Throughout his poetry, prose and drama, is repeated anew the theme of Myself/Other, the desire to achieve absolute perfection, such as Icarus, and the failure of this fulfillment. In texts like the well known «Quasi» and «7» poems as well as in the «A Confissão de Lúcio» novel, it is clearly present this wish for the merge between Myself and the Other and the impossibility of achieving it. Mário de Sá-Carneiro was, together with Fernando Pessoa, one of the founders of the Portuguese Modernism and one of the directors of «Orpheu» magazine. Both poets created several important isms for the Portuguese Modermism: paulismo, interseccionismo, sensacionismo. Nevertheless they kept themselves loyal to their own styles.

Keywords: Sá-Carneiro. Myself/Other. Modernism. Contemporary.

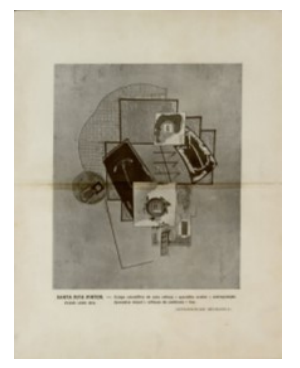

